\title{
APRENDIZAGEM AUTÔNOMA E WEBQUEST: EXPERIÊNCIAS DE APRENDIZES PÓS-GRADUANDOS EM UM AMBIENTE VIRTUAL DE APRENDIZAGEM
}

\author{
AUTONOMOUS LEARNING AND WEBQUEST: EXPERIENCES FROM \\ POSTGRADUATE STUDENTS IN A VIRTUAL LEARNING ENVIRONMENT
}

\author{
Fernanda Franco Tiraboschi \\ Universidade Federal de Goiás, Brasil \\ nandafranco87@yahoo.com.br
}

\begin{abstract}
RESUMO: Este trabalho tem como objetivo investigar as experiências de alunos de pósgraduação (professores em formação continuada) com atividades desenvolvidas por meio da ferramenta WebQuest, no intuito de observar indícios de autonomia por parte dos aprendizes pós-graduandos. Este estudo busca, também, observar as eventuais mudanças nas percepções dos alunos quanto ao seu papel de professor de línguas. $O$ enfoque teórico que norteia esta pesquisa abarca as noções do construto autonomia, tanto na perspectiva do aprendiz quanto do professor (BENSON, 1997; 2008; DICKINSON, 1994; MOURA FILHO, 2009; PAIVA, 2005), bem como da WebQuest enquanto um recurso eficiente na aprendizagem (CHRISTIE, 2007; DIAS, 2010; MARCH, 2004). Esta investigação se configura como um estudo de caso. Para a geração dos dados, são utilizadas as respostas de nove participantes a questionários elaborados em um ambiente virtual criado no WIGGIO, bem como a observação da realização das atividades. Os resultados mostram que as atividades propostas por meio da ferramenta WebQuest favorecem a autonomia dos aprendizes pós-graduandos no que tange à construção de conhecimento e, por conseguinte, a mudança significativa de posturas em relação à aprendizagem.
\end{abstract}

PALAVRAS-CHAVE: aprendizagem autônoma; WebQuest; ensino e aprendizagem de línguas.

ABSTRACT: This paper aims at investigating experiences from students (postgraduate teaching apprentices) with activities developed through the WebQuest tool in order to observe traces of autonomy by the postgraduate students. This research also sought to scrutinize possible changes in students' perceptions regarding their role as a language teacher. The theoretical approach that guided this investigation encompassed the notions of autonomy, both from the learner's and the teacher's perspectives (BENSON, 1997; 2008; DICKINSON, 1994; MOURA FILHO, 2009; PAIVA, 2005), as well as the use of WebQuest as an efficient tool for learning (CHRISTIE, 2007; DIAS, 2010; MARCH, 2004). In this case study, data were generated by the observation of the activities' accomplishment and the responses of nine of the participants to a questionnaire designed in the virtual environment. The results showed that the activities proposed through the WebQuest tool provided the postgraduate students with autonomy in the knowledge construction and, therefore, it was possible to notice significant changes in their attitudes in relation to learning.

KEYWORDS: autonomous learning; WebQuest; English teaching and learning. 


\section{Considerações iniciais}

A educação tradicional atribuía à instituição escolar o papel de formar indivíduos úteis, produtivos e obedientes. Tal sujeito agia conforme às imposições das instituições sociais, dessa forma, não possuía autonomia para tomar as rédeas de sua própria vida (FOUCAULT, 2012). Na contemporaneidade, também chamada de era da sociedade de informação, podemos notar a necessidade de sujeitos mais críticos, autônomos e aptos a tomarem suas próprias decisões e a participarem de forma mais ativa nas práticas sociais. Entretanto, no contexto escolar prevalece ainda o sistema educacional tradicional, no qual o professor transmite o conhecimento "necessário" à formação do aprendiz (FREIRE, 2015; SILVA, 2013). A esse respeito, Freire (2015) ressalta que ainda estamos enraizados em uma educação centrada no professor que reforça a postura passiva do aprendiz diante das situações de construção de conhecimento. Nesse sentido, Paiva e Vieira (2005, s/p) afirmam que "é bem difícil imaginar um aprendiz autônomo que tenha como instrutor um professor tradicional que limita o crescimento do aprendiz, não deixando que ele trace seu próprio caminho e mantendo-o atado ao seu método rígido e inflexível de ensinar".

Desse modo, surge a necessidade de pensarmos em uma reorganização dos atributos de professores e de alunos no tocante à construção de conhecimentos. Se entendermos que o papel do professor é o de contribuir para a formação de sujeitos aptos a atuarem ativamente na sociedade contemporânea, então devemos pensar nas mudanças de atitudes que essa decisão implica. Para tanto, podemos buscar meios para desenvolver a aprendizagem autônoma de aprendizes por meio de práticas que possibilitem a tomada de decisões e o gerenciamento do próprio processo de aprendizagem.

A autonomia pode ser compreendida como uma atitude em relação à aprendizagem, isto é, a assunção da responsabilidade pela própria aprendizagem por parte dos aprendizes (DICKINSON, 1994). Nessa linha, torna-se fundamental deslocar a ênfase que ainda permanece na prática do professor para uma prática mais centrada no aprendiz. Dessa maneira, o professor passa a ser um facilitador da aprendizagem em vez de um mero transmissor de informações, e o aprendiz se torna responsável por sua própria aprendizagem. Assim, em um primeiro momento, é preciso levar em conta as necessidades do aprendiz, e, posteriormente, buscar os recursos que melhor atendam a tais necessidades.

No âmbito do ensino e aprendizagem de línguas estrangeiras, um número considerável de pesquisadores tem demonstrado a necessidade de mudança de atitudes dos atores envolvidos no processo de educação linguística, de forma a estimular a implementação de rotinas instrucionais que auxiliem os aprendizes a participarem ativamente no controle e gerenciamento de sua própria aprendizagem (BENSON, 1997).

Ao considerar que a universidade consiste na entidade formadora dos profissionais que atuarão na instituição escolar, faz-se necessário não só uma reflexão teóricometodológica acerca da aprendizagem autônoma nos cursos de formação de professores, mas também a prática de atividades que proporcione o desenvolvimento da autonomia dos professores aprendizes, uma vez que esses tendem a adotar as práticas pedagógicas já vivenciadas (FREEMAN; JOHNSON, 1998; NÓVOA, 2015).

Nóvoa (2015) argumenta que a articulação da prática à teoria é necessária desde a 
formação inicial dos professores. Para o autor, tal articulação é indispensável na transformação do processo de ensinar e aprender nas escolas. Por conseguinte, se tomarmos o conceito de formação de professores como o processo de aprendizagem para ensinar (FREEMAN; JOHNSON, 1998), torna-se imprescindível que os cursos de formação, seja em estágio inicial ou continuada, proporcionem práticas autônomas aos professores, para que esses profissionais possam, também, estimular a autonomia de seus alunos.

Diversas pesquisas no campo da Linguística Aplicada têm demonstrado contribuições significativas das Tecnologias Digitais de Informação e Comunicação (TDICs) ao desenvolvimento da autonomia de aprendizes de línguas (OLIVEIRA, 2013; PAIVA, 2009; WARSCHAUER, 1996; 2010). Nesse sentido, é possível que o professor utilize tais recursos, de forma a contribuir para o desenvolvimento de aprendizes mais autônomos; entretanto, é necessário que este desempenhe o papel de facilitador. Nessa direção, Paiva e Vieira (2005, s/p) afirmam que "o comportamento autônomo de um aprendiz pode estar diretamente relacionado ao tipo de comportamento que o professor apresenta em sala de aula". Desse modo, cabe ao professor não só lançar mão das ferramentas que possam atender às necessidades de aprendizagem dos aprendizes, mas também assumir uma postura mais flexível no intuito de promover uma participação mais ativa e o envolvimento do aprendiz em seu próprio processo de aprendizagem.

Dias (2012, p. 4) argumenta que recursos disponibilizados pelas TDICs, em especial a WebQuest, "podem favorecer a formação do professor para as mudanças advindas da complexidade das inter-relações da era virtual". Nesse sentido, é possível afirmar que tais recursos oportunizam ações autônomas do professor em formação e, consequentemente, sua postura como docente.

Partindo dos pressupostos mencionados anteriormente, surgiram as seguintes questões: a) De que modo a WebQuest pode favorecer o desenvolvimento da autonomia de professores em formação continuada? b) Quais as percepções dos alunos de pósgraduação no tocante ao seu papel de discente e de docente após a realização de atividades com WebQuest? No intuito de responder a essas perguntas, este estudo investigou as experiências dos alunos participantes (professores em formação continuada) em uma comunidade virtual de aprendizagem criada no sítio eletrônico WIGGIO em relação às atividades desenvolvidas por meio da ferramenta WebQuest, com vistas à identificação de indícios de ações autônomas por parte dos aprendizes pósgraduandos. Esta pesquisa procurou ainda observar as eventuais mudanças nas percepções dos alunos quanto ao seu papel de aprendiz, bem como no de professor, durante as atividades desenvolvidas. Foi possível notar que as atividades propostas por meio da ferramenta mencionada favoreceram a autonomia dos aprendizes pósgraduandos no que diz respeito à construção de conhecimento.

Este artigo se organiza em quatro seções, além das considerações inicias e finais. $\mathrm{Na}$ primeira seção, serão discutidos alguns aspectos relacionados à WebQuest enquanto um recurso eficiente na aprendizagem. Na sequência, serão apresentadas as noções do construto autonomia que embasam este estudo. Em seguida, serão expostos os aspectos metodológicos deste trabalho. Por fim, serão analisadas as atividades a partir da WebQuest, bem como as respostas dos participantes a um questionário elaborado a partir do recurso enquete do WIGGIO. Este trabalho ainda inclui referências bibliográficas. Tendo apresentado as considerações iniciais, passemos à primeira seção. 


\title{
2 WebQuest: um ambiente de aprendizagem favorável à autonomia do aprendiz
}

A WebQuest pode ser entendida como um recurso por meio do qual é possível criar uma atividade voltada para a pesquisa em que a web é a principal fonte para o desenvolvimento/realização da investigação/estudo. De acordo com Dias (2010, p. 2), a WebQuest consiste em "um artefato tecnológico que promove o desenvolvimento do aprendizado crítico, a coconstrução de conhecimento, a reflexão do que foi aprendido e a transferência para outros domínios da vida acadêmica e pessoal dos envolvidos". A autora ainda acrescenta que a WebQuest pode ser vista como "ambientes virtuais de aprendizagem colaborativa online que permitem o desenvolvimento de projetos de pesquisa pelo uso da web e seus recursos" (ibid., p. 2).

O primeiro modelo de WebQuest foi desenvolvido por Bernie Dodge e Tom March na Universidade de San Diego. Vale ressaltar que uma WebQuest pode ser criada a partir de diversos recursos on-line e também off-line, tais como Word, Powerpoint, e até Excel, desde que se crie um documento com hyperlinks e contenha todos os atributos críticos necessários à ferramenta (MARCH, 2004).

Christie (2007) descreve as etapas que compõem essa ferramenta na seguinte ordem: Introdução (Orientação em relação ao que está por vir); Tarefa (descrição do que o aprendiz terá que realizar); Processo (sugestão de passos que o aprendiz terá que seguir para a realização da tarefa); Recursos (lista de páginas da Web que poderá auxiliar o aprendiz em tal tarefa); Avaliação (exposição das formas, critérios e aspectos que serão utilizados); e Conclusão (etapa na qual é possível proporcionar um fechamento através do resumo da experiência e o estímulo à reflexão sobre o processo). É possível ainda, conforme Dias (2010), acrescentar um componente denominado Créditos, no qual as referências são citadas e agradecimentos aos envolvidos no processo são evidenciados.

Essa ferramenta pode proporcionar benefícios ao processo de ensino e aprendizagem em geral, tais como: (1) promover a modernização dos meios utilizados no processo de ensino e aprendizagem, o que faz com que se tornem mais condizentes com a atualidade; (2) proporcionar uma aprendizagem colaborativa, na qual a interação é fundamental e um de seus benefícios possíveis é que o aluno passe de um estágio de total dependência para autonomia; (3) possibilitar informações autênticas e atualizadas; e (4) desenvolver habilidades cognitivas e metacognitivas.

De acordo com Christie (2007), ao propor uma atividade via WebQuest, o professor pode proporcionar ao aprendiz a oportunidade de fazer parte como um membro ativo na construção do conhecimento. Adicionalmente, March (2004, s/p) argumenta que tal ferramenta pode ajudar os aprendizes a "construir uma compreensão profunda e se moverem em direção a um processo educacional mais autônomo e centrado na aprendizagem"1.

\section{Autonomia na aprendizagem de línguas: foco no aprendiz e no professor}

\author{
Ao tratar da concepção de autonomia, de um modo geral, é importante considerar
}

1 Original: "construct a deeper understanding and move through a crucial transition phase toward a more autonomous, learning-centered educational process (MARCH, 2004, s/p)". 
diferentes perspectivas que proporcionam pontos de vistas distintos sobre o mesmo fenômeno. Benson (1997) sugere que o conceito de autonomia possa ser visto sob o viés técnico, psicológico e político, estabelecendo uma relação com as perspectivas positivista, construtivista e crítica. Ao considerar que a maioria dos respondentes deste estudo são aprendizes e atuam também como professores, faz-se necessário buscar na literatura sobre autonomia subsídios para uma análise mais consistente. Dessa forma, busca-se, neste trabalho, abordar o conceito de autonomia, no âmbito do ensino e aprendizagem de línguas, tomando-se por base as perspectivas do professor e do aprendiz.

Al-busaidi e Borg (2012, p. 5) discutem alguns pressupostos teóricos que apoiam o conceito de autonomia, salientando que tais posturas teóricas podem divergir da maneira como os professores entendem esse conceito. Conforme os autores mencionados, 0 conceito de autonomia pode ser visto a partir das perspectivas técnica, psicológica, política e sociocultural (BENSON, 1997; OXFORD, 2003, citado por AL-BUSAIDI; BORG, 2012). Nesse sentido, os autores discutem o posicionamento de cada perspectiva nesses termos:

enquanto uma perspectiva técnica incide sobre as configurações físicas de aprendizagem (muitas vezes fora de contextos educativos formais), uma orientação psicológica está preocupada com os atributos mentais que permitem a autonomia, e enquanto uma perspectiva política (ou crítica) se concentra em questões de poder e controle, uma perspectiva sociocultural tem um interesse central nas funções de interação e participação social no desenvolvimento da autonomia do aluno (AL-BUSAIDI; BORG, 2012, p. 5).

De acordo com Dickinson (1987, citado por BENSON, 2008), a autonomia do aprendiz diz respeito a uma liberdade de aprendizagem fora dos domínios de uma instituição. Nessa direção, o aprendiz se responsabiliza por todas as decisões relativas à sua aprendizagem sem intervenção ou envolvimento do professor ou instituição. Contudo, Benson (2008) argumenta que tal visão se restringe a uma dimensão situacional, e sugere que a autonomia seja entendida dentro e fora dos limites das instituições sociais, já que a aprendizagem não é apenas a preparação para a vida, mas uma parte da mesma.

É possível encontrar pontos de convergência na definição de autonomia proposta por Paiva e a ideia de autonomia sugerida por Benson (2008). Desse modo, a autonomia pode ser compreendida, nas palavras de Paiva (2005), como:

um sistema sócio-cognitivo complexo, sujeito a restrições internas e externas. Ela se manifesta em diferentes graus de independência e controle sobre o próprio processo de aprendizagem, envolvendo capacidades, habilidades, atitudes, desejos, tomadas de decisão, escolhas, e avaliação tanto como aprendiz de língua ou como seu usuário, dentro ou fora da sala de aula (PAIVA, 2005, p. 88-89).

Nessa linha de pensamento, o desenvolvimento de uma aprendizagem mais autônoma não prescinde da intervenção de um professor, pois conforme Little (1991, citado em MOURA FILHO, 2009, p. 258), "a autonomia não é autoinstrução ou aprendizagem sem professor, não envolve o banimento das intervenções ou iniciativas do professor no processo de aprendizagem". Ao considerar que o aluno pode demorar muito tempo para desenvolver um nível adequado de autonomia por conta própria, cabe ao 
professor munir-se das estratégias necessárias para a elaboração de atividades que possam impulsionar e viabilizar o desenvolvimento progressivo da autonomia dos aprendizes no que tange à construção do próprio conhecimento.

$\mathrm{Na}$ perspectiva do professor, proporcionar o desenvolvimento da autonomia no aprendiz pode resultar em problemas de ordem prática. Benson (2008, p. 25) afirma que

definir a direção para a própria aprendizagem é, em outras palavras, muito mais uma questão de determinar os próprios objetivos e os conteúdos de aprendizagem. O controle do aprendiz sobre objetivos de aprendizagem e conteúdo pode ser particularmente problemático para os professores em sala de aula (BENSON, 2008, p. 25)².

Nessa mesma direção, Paiva e Vieira (2005, s/p) advogam que "dificilmente um aprendiz, no contexto escolar, terá o direito de escolher objetivos, conteúdos, métodos, pois a estrutura de poder escolar não dá margem para ações autônomas. No entanto, os alunos podem ter iniciativas paralelas ao contexto escolar formal". Em outras palavras, os aprendizes podem assumir atitudes que os levem a experienciar situações de aprendizagem fora do contexto educacional formal.

Vale ressaltar que a autonomia do professor consiste em um fator relevante no processo de autonomia na aprendizagem. Little (1995), citado por Sinclair (2008, p. 243), define os professores autônomos como aqueles que possuem "um forte senso de responsabilidade pessoal para com o seu ensino, exercitam através da reflexão e análise contínua no mais alto grau possível de controle afetivo e cognitivo do processo de ensino e exploram a liberdade que isto lhes confere" ${ }^{3}$. Dessa forma, como mencionado anteriormente, o tipo de comportamento que o professor assumir em sala de aula poderá estimular ou não a autonomia do aprendiz no tocante a sua própria aprendizagem (PAIVA; VIEIRA, 2005).

Cabe salientar, conforme Sinclair (2008) alerta, que uma das formas de exercer a autonomia do professor diz respeito a sua participação espontânea em cursos de formação continuada. Desse modo, a autonomia do aprendiz está estritamente relacionada à autonomia do professor, visto que o professor pode promover atividades automonitoradas que, por sua vez, podem estimular os aprendizes a tomar suas decisões em termos do que e como aprender. Benson (2008) argumenta que professores e aprendizes podem ter pontos de vista diferentes em relação ao processo de autonomia na aprendizagem. Assim, o deslocamento da posição de professor para aprendiz pode ocasionar uma mudança na maneira de compreender tal processo.

Para Benson (2008, p. 15), os professores tendem a ver a autonomia do aprendiz como a assunção do "controle de um programa de ações cuja legitimidade subjacente é inquestionável". Já os aprendizes tendem a ver a autonomia, que para o referido autor não se trata de uma visão oposta à do professor, mas tangencial, como a preocupação

2 Original: "setting the direction for one's own learning is, in other words, much more a matter of determining one's learning objectives and contents. The learner's control over his/her own learning and content goals can be particularly problematic for teachers in the classroom" (BENSON, 2008, p. 25).

3 Original: "having a strong sense of personal responsibility for their teaching, exercising via continuous reflection and analysis the highest possible degree of affective and cognitive control of the teaching process, and exploring the freedom that this confers" (LITTLE, 1995, p.179, citado por SINCLAIR, 2008). 
"com a aprendizagem, em um sentido muito mais amplo, e sua relação com a vida para além da sala de aula" (BENSON, 2008, p. 15).

Em síntese, podemos perceber que o termo autonomia pode ser compreendido de diversas formas, desde as posições mais radicais até as mais flexíveis. Dessa maneira, é possível dizer que a autonomia do aprendiz é entendida como a postura mais ativa do aprendiz na construção de seu próprio conhecimento de forma que este possa estabelecer os objetivos e tomar as decisões que melhor atendam às suas necessidades de aprendizagem. Paiva e Vieira (2005, s/p) argumentam que um aprendiz autônomo não é "um aprendiz individualista, que não frequenta aulas e que não se relaciona com o professor ou com outros aprendizes". As autoras ainda acrescentam que "o exercício da autonomia é algo que pode ser alcançado por qualquer aprendiz, desde que o mesmo tome a direção de seu processo de aprendizagem" (PAIVA; VIEIRA, 2005, s/p).

\section{Os aspectos metodológicos do estudo}

Com o advento das TDICs, a possibilidade de criação de ambientes on-line para fins educativos tem se tornado frequente nas diversas áreas do saber humano. Um número significativo de pesquisas tem demonstrado as contribuições que tal contexto pode proporcionar ao processo de ensino e aprendizagem, de forma a possibilitar não só recursos extras às aulas presenciais, mas também a execução de cursos à distância. É muito comum se referir a esse contexto utilizando a expressão Ambiente Virtual de Aprendizagem (AVA). Assim, o AVA pode ser entendido como um contexto de aprendizagem baseado na Internet, ou, em outros termos, trata-se de uma educação ou aprendizagem on-line à distância, a partir de interações síncronas ou assíncronas, que, na maioria das vezes, ocorre de forma colaborativa.

Dentre as abordagens metodológicas sob o paradigma qualitativo, o Estudo de Caso consiste na opção mais adequada devido a uma série de fatores que, considerada a natureza deste estudo, podem contribuir para uma melhor compreensão do objeto de estudo. O contexto desta pesquisa consiste em um ambiente virtual de aprendizagem (AVA) criado gratuitamente no sítio eletrônico WIGGIO. O AVA em estudo foi criado para a realização de uma disciplina semipresencial voltada para o uso de novas tecnologias no ensino e aprendizagem de línguas. No decorrer do curso, foram propostas diversas atividades no intuito de explorar as ferramentas que estavam disponíveis no próprio AVA, bem como atividades com uso de outros recursos das TDICs.

Esta investigação tem como foco de análise a prática de atividades de uma turma de pós-graduandos em Letras e Linguística a partir da utilização de WebQuests em um ambiente virtual de aprendizagem. Na primeira atividade proposta com o uso da WebQuest, o objetivo final da tarefa consistiu na criação de um infográfico. Na segunda atividade, foi proposto aos participantes um estudo sobre a WebQuest através de uma WebQuest, isto é, eles foram estimulados a pesquisarem sobre o conceito, bem como os pressupostos teóricos subjacentes a essa ferramenta. Esse tipo de atividade demonstra ser eficiente em cursos de formação continuada, pois conforme Schön (1983, citado por 
Dias, 2012, p. 11), os professores têm a oportunidade de "conhecer na ação, refletir na e sobre a ação". Dessa forma, para a ilustração e análise dos dados, o foco central recai sobre a segunda proposta, visto que esta proporciona uma visão de autonomia na perspectiva do aprendiz e do professor. Na Figura 1, podemos visualizar a primeira página da WebQuest em estudo:

\author{
Atividade da Semana \\ \begin{tabular}{|l|l|l|l|l|l}
\hline Introduction & Task & Process & Evaluation & Conclusion \\
\hline
\end{tabular} \\ $\mathrm{Na}$ atividade realizada nas duas últimas semanas a tarefa foi apresentada por meio de uma WebQuest. \\ Uma WebQuest é, grosso modo, uma proposta de atividade orientada para a pesquisa, cujo propósito é levar o aluno \\ a adquirir e integrar conhecimentos por meio dos recursos da própria internet.
}

Nesta semana, iremos explorar as características e possibilidades de mais uma ferramenta da web 2.0 .

Figura 1: Introdução da WebQuest.

Fonte: Printscreen de <http://www.createwebquest.com/ecaol2/atividade-da-semana-0>.

Para a geração dos dados, foi utilizada uma enquete disponibilizada no AVA. A escolha desse instrumento para geração de dados refere-se ao fato de que essa ferramenta proporciona uma organização prévia, de maneira a facilitar a análise destes. $O$ grupo de alunos era composto por dezesseis integrantes. Contudo, apenas nove participantes assinaram o Termo de Consentimento Livre e Esclarecido e, por isso, os dados contemplados, neste estudo, foram gerados a partir das respostas desses participantes. O questionário foi dividido em duas partes. As questões constituintes da primeira parte tiveram como objetivo extrair informações acerca do perfil dos participantes, bem como suas experiências anteriores ao curso, principalmente no que diz respeito ao uso de recursos tecnológicos, tanto nas práticas cotidianas quanto pedagógicas. Na segunda parte, as questões tinham como objetivo obter informações acerca das contribuições das atividades via WebQuest no que se refere às mudanças nos modos de aprender e ensinar dos participantes em estudo.

\title{
5 A proposta de atividade via WebQuest e seu impacto nas percepções dos aprendizes pós-graduandos
}

Conforme discutido na seção do referencial teórico, a autonomia consiste em um construto bastante complexo, que pode ser visto a partir de diferentes ângulos. Nesse sentido, a complexidade subjacente à noção de autonomia pode gerar confrontos teóricos concernentes à abordagem de tal construto. Buscou-se, contudo, partir dos pressupostos pertinentes às perspectivas técnica, psicológica, política e sociocultural, visando a uma abordagem mais ampla e completa do conceito de autonomia, para, em um segundo momento, atribuir uma ênfase maior à dimensão individual e social a partir do viés do 
professor e do aprendiz.

Sob essa ótica, foi possível observar que os resultados do questionário revelaram indícios de aspectos sociais e individuais de autonomia relativas tanto à postura dos pósgraduandos enquanto aprendizes quanto no que se refere a suas práticas pedagógicas. Outro aspecto que pôde ser observado diz respeito às contribuições da WebQuest para a aprendizagem autônoma tanto na perspectiva do professor quanto do aprendiz. Tal constatação corrobora o conceito de autonomia enquanto um fenômeno sociocognitivo complexo (PAIVA, 2005).

Os resultados evidenciaram, também, que a maioria dos respondentes estava em exercício, isto é, atuava como professores em diversas instituições de ensino. Outro aspecto relevante relatado pelos respondentes refere-se à utilização de recursos disponibilizados pelas TDICs em suas práticas pedagógicas. Do total de respondentes, 90\% afirmaram fazer uso de ferramentas durante ou concomitantemente a suas aulas. Entretanto, 80\% afirmaram que nunca tiveram nenhuma experiência com a proposta de atividades via WebQuest anterior à disciplina. Ao discorrerem sobre os diferentes recursos elencados em suas aulas, foi possível notar indícios de incentivos a uma reflexão por parte do aprendiz em relação ao seu próprio processo de aprendizagem. Tal prática sugere uma postura em direção a uma aprendizagem mais autônoma. Söntengs (1999, p. 567), citado por Paiva (2005, s/p), afirma que a "colaboração e reflexão são aspectos de autonomia, sendo a reflexão um elemento vital para que o aprendiz se torne mais autônomo". Essa atitude pode ser observada no excerto seguinte:

[1] Sim, utilizo vídeos do youtube, blogs que incentivo os alunos a fazer sobre o contexto local, gravação de aulas com câmera para os próprios alunos perceberem seus erros ou enganos durante as produções orais e se corrigirem com minha ajuda e a ajuda dos colegas.

(Participante 8 - Resposta ao questionário)

É possível dizer que os aspectos relacionados à ferramenta WebQuest que mais chamaram a atenção dos respondentes referem-se à interação e à autonomia no processo de aprendizagem. De acordo com Al-busaidi e Borg (2012), os termos prevalecentes encontrados na literatura relacionada à autonomia englobam aqueles que suportam "conceitos como liberdade, controle, responsabilidade, escolha e independência". Tais termos podem ser evidenciados nos excertos que seguem:

[2] A forma interativa e colaborativa ofertada ao discente ao desenvolver uma atividade e a autonomia em buscar novas informações online para resolver as atividades pelo docente.

(Participante 1 - Resposta ao questionário)

[3] A praticidade e a maneira como alia práticas pedagógicas a assuntos de interesse dos alunos. Além disso, também é interessante a ideia de uma atividade realizada no próprio computador do aluno, mas mantendo o contato do mesmo com outros colegas.

(Participante 2 - Resposta ao questionário)

[4] Principalmente o fato de conferir grande autonomia ao aluno incentivando-o à pesquisa.

(Participante 3 - Resposta ao questionário)

[5] O fato de os alunos trabalharem em grupo de maneira mais independente, sem tanta 
interferência do professor, e poderem pesquisar por informações online, em vez de apenas olhar no livro.

(Participante 4 - Resposta ao questionário)

Com base nos excertos 2, 3, 4 e 5, é possível afirmar que a autonomia na aprendizagem não se refere a uma capacidade de construção de conhecimento totalmente individual, fora de um contexto educacional formal e sem interação social. É importante considerar também a dimensão social da autonomia. Söntengs (1999, p. 567) defende que os ambientes virtuais de aprendizagem podem favorecer "um trabalho em grupo colaborativo e reflexivo que ajudará os alunos a se tornarem aprendizes de línguas mais autônomos". Dessa forma, podemos dizer que a colaboração e a interação social desempenham papéis relevantes na promoção do desenvolvimento da autonomia do aprendiz. Tal fato pode ser evidenciado também no excerto 6 , no qual o participante descreve suas impressões relativas à realização das tarefas em pares/grupos por meio da WebQuest.

[6] Me sinto estimulado quando a formatação da WebQuest permite que eu siga múltiplos caminhos, tanto de busca, quanto de resultados e de reflexões. O trabalho colaborativo é estimulante, desde que sejam respeitados os momentos para que cada membro do grupo elabore os conceitos "na própria cabeça", sem ter que estar o tempo todo tendo que interagir com os colegas. Meu estilo de aprendizagem é $50 \%$ individual e $50 \%$ baseado em trocas e trabalho colaborativo, então é por isso que estou chamando a atenção para este fato. Colaboração em excesso fica muito forçada; trabalho isolado em excesso gera falta de perspectivas que advém dos múltiplos olhares. É preciso então, a meu ver, equilibrar as duas coisas. O trabalho assíncrono, que é comum nos ambientes virtuais, me atende nesse quesito, e WebQuests que equilibram o fazer colaborativo com o reelaborar individual me atendem também. Espero ser capaz de atingir esse equilíbrio nas WebQuests que eu mesmo criar para meus alunos, rs.

(Participante 6 - Resposta ao questionário)

Está evidente nesse excerto que a forma como a proposta via WebQuest foi elaborada impulsionou a colaboração entre os participantes, bem como a autonomia destes na execução da tarefa. Vale ressaltar que a ferramenta por si só não garante uma eficácia dos aprendizes. Em outras palavras, não é somente a ferramenta, mas também a forma como é utilizada que determina os benefícios que tal ferramenta pode trazer. A utilização de uma WebQuest bem elaborada, por exemplo, pode favorecer o desenvolvimento da aprendizagem autônoma.

Cabe salientar que o incentivo a refletir na e sobre a ação (SCHÖN, 1983, citado por DIAS, 2012, p. 11) proporcionou um conhecimento experiencial, bem como teóricometodológico, que se fazem essenciais e significativos na formação do professor. Desse modo, faz-se necessário observar também os fatores pertinentes à proposta que contribuíram para que os aprendizes tomassem atitudes mais autônomas. No quadro, a seguir, podemos observar os objetivos subjacentes as etapas que constituíram a WebQuest em estudo. 
http://periodicos.letras.ufmg.br/index.php/textolivre

Belo Horizonte, v. 12, n. 2, p. 135-151, mai.-ago. 2019 - ISSN 1983-3652 DOI : $10.17851 / 1983-3652 \cdot 12 \cdot 2 \cdot 135-151$

Quadro 1: Descrição dos objetivos de cada etapa da WebQuest

\begin{tabular}{|l|l|}
\hline \multicolumn{1}{|c|}{ Etapas } & \multicolumn{1}{|c|}{ Objetivos } \\
\hline Introdução & $\begin{array}{l}\text { Introduzir o conceito de WebQuest de um modo sucinto e apresentar o } \\
\text { objetivo geral da atividade proposta. }\end{array}$ \\
\hline Tarefa & $\begin{array}{l}\text { Fazer a proposta de atividade que consistiu na avaliação das } \\
\text { potencialidades do uso de WebQuest na prática voltada para o ensino e } \\
\text { aprendizagem de línguas. }\end{array}$ \\
\hline Processo & $\begin{array}{l}\text { Sugerir ações ou passos para a realização da atividade. Foram sugeridos } \\
\text { dois passos: 1) Visitar links com WebQuest elaboradas por outras } \\
\text { pessoas, analisá-las e, posteriormente, postar comentários no WIGGIO; } 2) \\
\text { Navegar pelos links com textos teóricos e, em seguida, gravar um } \\
\text { comentário em vídeo a partir da ferramenta video note disponibilizada no } \\
\text { próprio WIGGIO. }\end{array}$ \\
\hline Avaliação & $\begin{array}{l}\text { Apresentar questões para que os alunos pudessem proceder a uma } \\
\text { autoavaliação no tocante a realização da atividade proposta. }\end{array}$ \\
\hline
\end{tabular}

Fonte: Elaborado pela autora com base na WebQuest em estudo.

No item processo, foram propostos os passos para a realização da tarefa em duas fases. Na primeira fase, os aprendizes observaram as características das WebQuests indicadas e postaram suas impressões no WIGGIO. Na segunda fase, aprofundaram no tema a partir de leituras teóricas tanto dos links indicados quanto de fontes pesquisadas pelos próprios participantes. É interessante ressaltar que as orientações foram precisas e flexíveis, isto é, o aprendiz contou com uma série de instruções que procurou facilitar a compleição da execução da tarefa, porém, possuía uma liberdade para buscar recursos que melhor atendessem às suas necessidades em relação à sua própria aprendizagem.

Conforme mencionado no parágrafo anterior, os alunos deveriam postar comentários no WIGGIO após avaliar as WebQuests sugeridas. Podemos notar nos comentários dos participantes uma atitude mais autônoma na busca por informações sobre a WebQuest. Além de refletirem sobre as características da WebQuest por meio dos links disponíveis na WebQuest proposta, os participantes buscaram por conta própria outros meios de adquirir conhecimento, como vídeos no youtube, blogs, wikis e outros tipos de sites que abordavam o tema em questão. Outro aspecto interessante diz respeito à colaboração dos participantes através do compartilhamento. Podemos perceber nos comentários postados não só as impressões dos participantes em relação à ferramenta eleita para estudo, mas também os compartilhamentos das fontes de estudos consideradas relevantes pelos participantes. Vale explicar que os nomes dos participantes foram omitidos no comentário em questão e substituídos por Participante 1 e 2. Observemos o comentário do Participante 3 para verificar as reflexões delineadas acima:

[7] Bom dia a todos.

Eu também havia me interessado pela ferramenta (que até então eu não sabia que se chamava WebQuest) quando a professora propôs a atividade dos infográficos. Achei uma forma muito criativa e organizada de trabalhar. Ao ver os exemplos que a professora apontou na atividade da semana 7 , percebi que a WebQuest é uma ferramenta de pesquisa - não sei se sempre realizada em grupos, mas no caso dos exemplos sim - em que o professor organiza orientações via internet, que será também fonte de pesquisa dos alunos. Quanto a estrutura da WebQuest, já foi muito bem explicada pela Participante 1 
quando aponta as etapas de introdução, tarefa, processos, recursos, avaliação e conclusão. Creio que é uma excelente ferramenta para a educação, uma vez que proporciona, ao mesmo tempo, certa autonomia para os alunos (como apontou o Participante 2) e desenvolvimento da habilidade de cooperação, em caso de trabalhos em grupo. Além disso, trata-se de um recurso versátil que pode ser utilizado por diversas áreas de conhecimento, e também para diferentes níveis, apesar de ser mais fácil utilizar ferramentas on-line com alunos mais velhos, como os do ensino médio. Caso seja uma atividade feita em sala de aula (de informática, no caso), acredito que se possa trabalhar mais facilmente com alunos menores, pelas dificuldades que o Participante 2 apresentou. Enfim, achei uma forma muito interessante e criativa de propor pesquisas, me parece que não é necessário utilizar programas específicos complicados demais e, por isso, me senti motivada a criar mesmo uma WebQuest, como a professor sugeriu. Abraço a todos!

(Participante 3 - Comentário postado no Wiggio)

Podemos evidenciar, também, a recorrência de termos como autonomia e colaboração nos comentários postados no WIGGIO. Tal fato corrobora a visão de Dias (2010, p. 2) em relação às contribuições da WebQuest para uma postura autônoma e colaborativa, uma vez que, para ela, a WebQuest pode ser vista como "ambientes virtuais de aprendizagem colaborativa on-line que permitem o desenvolvimento de projetos de pesquisa pelo uso da web e seus recursos" (DIAS, 2010, p. 2). Outro aspecto que pode ser destacado é a visão da ferramenta enquanto aprendiz e professor, conforme podemos ver no exemplo 7.

Após os comentários, partiu-se para a segunda fase da tarefa, que tinha como objetivo final a criação de um vídeo em grupo sobre o conceito de WebQuest, conforme pode ser observado no Quadro 1. As instruções visavam nortear os participantes no processo de realização da tarefa, entretanto, a proposta não estabelece nenhuma rigidez quanto aos meios para se alcançar o objetivo final. Essa flexibilidade na condução da atividade faz-se necessário na prática do professor que almeja desenvolver um aprendiz autônomo. Discutindo sobre suas impressões em relação ao papel do professor frente à utilização da WebQuest, o participante 7 corrobora a ideia exposta anteriormente.

[8] Depende de como o professor enxerga seu papel. Se for um professor que se enxerga como alguém que deve orientar o processo de aprendizagem dos seus alunos, sem ter que ser o detentor de todas as informações, então acho que a WebQuest só reforça positivamente e auxilia essa linha de pensamento e de trabalho. Se for um professor que não encara o planejamento e a aprendizagem contínua e a aprendizagem do novo como algo necessário e inerente ao seu papel, a WebQuest será uma experiência sofrida para esse professor.

(Participante 7 - Resposta ao questionário)

É possível observar que o desenvolvimento da autonomia não é "simplesmente uma questão de colocar os aprendizes em uma situação em que eles devem ser independentes" (AL-BUSAIDI; BORG, 2012, p 5). O desenvolvimento da autonomia envolve fatores mais complexos, como a consciência em relação ao próprio processo de aprendizagem, bem como a reflexão e pensamento crítico no que tange às escolhas e decisões necessárias a esse processo. Foi possível notar na etapa de Avaliação, um estímulo à conscientização e reflexão em relação ao processo de aprendizagem por meio da autoavaliação. No quadro que segue, são apresentados os elementos utilizados para proporcionar ao participante a autoavaliação. 
Quadro 2: Autoavaliação

\begin{tabular}{|l|l|}
\hline \multicolumn{1}{|c|}{ Critério } & \multicolumn{1}{c|}{ Questões para reflexão } \\
\hline Atitudes & Colaborei nas atividades? \\
& Compartilhei informações? \\
& Fui autônomo(a)? \\
& Tomei iniciativa? \\
& Cumpri o tempo e os prazos previstos? \\
\hline Conteúdos & $\begin{array}{l}\text { Selecionei outras informações pertinentes e relevantes? } \\
\text { Mobilizei conhecimentos anteriores? }\end{array}$ \\
& Construí novos conhecimentos? \\
\hline
\end{tabular}

Fonte: Elaborada pela autora com base na WebQuest em estudo.

É interessante salientar que os itens sugeridos para direcionar a auto e a coavaliação proporcionam subsídios para uma reflexão mais profunda em relação ao desempenho dos aprendizes. Ao possibilitar uma tomada de consciência em relação ao processo de aprendizagem, os aprendizes podem tomar decisões por conta própria no intuito de alcançar bons resultados. Blanche e Merino (1989) citam alguns benefícios que podem ser atribuídos à prática autoavaliativa no processo de aprendizagem. Dentre os fatores elencados, estão: o aumento do nível de consciência dos aprendizes sobre suas habilidades; o aumento da motivação; o desenvolvimento da autonomia e; 0 desenvolvimento da autoconfiança e autoeficácia.

É possível observar os efeitos positivos da prática de autoavaliação na postura dos participantes enquanto aprendizes. Observe a fala do participante 3 no excerto 9.

[9] Sim, senti que houve mais interesse em realizar a atividade, e mesmo mais cobrança pelo fato de haver uma autoavaliação incluída no processo.

(Participante 3 - Resposta ao questionário)

Ainda na perspectiva do aprendiz, é bastante recorrente, na literatura sobre autonomia, a ideia de que a autonomia envolve uma vontade por parte do aprendiz de assumir a responsabilidade por sua própria aprendizagem (AL-BUSAIDI; BORG, 2012; BENSON, 1997; DICKINSON, 1994). Desse modo, podemos verificar no excerto 10 indícios de que a proposta da WebQuest, em questão, impulsionou uma mudança em relação à postura dos participantes em relação a seus papéis de aprendizes.

[10] Creio que essas atividades deixaram bem claro que o conhecimento não é simplesmente transferido, é construído a partir do trabalho colaborativo, o aprendiz também é responsável pelo processo. Sinto que minha postura ainda precisa de mais mudanças.

(Participante 4 - Resposta ao questionário)

Na perspectiva do professor, é possível notar pistas de mudanças em direção a uma postura mais autônoma no tocante à prática pedagógica. Benson (2008 p. 18) argumenta que uma "educação adequada é aquela que oferece às pessoas as 
capacidades que elas precisam para levar uma vida mais autônoma" ${ }^{5}$. Nesse sentido, o autor ainda defende que a autonomia deve ser exercida em todos os âmbitos da vida, incluindo as nossas ações enquanto aprendizes e professores. Nessa linha, o professor autônomo é aquele que se desprende do engessamento decorrente de currículos fixos e rígidos e reflete sobre as reais necessidades de seus aprendizes, de modo a considerar as limitações e subjetividades do sujeito aluno. É aquele que proporciona situações de aprendizagem nas quais o aprendiz terá a oportunidade de interagir, colaborar com pares, coconstruir conhecimentos, refletir de maneira consciente sobre seus estilos de aprendizagem e tomar decisões sobre as estratégias mais eficientes para alcançar seus objetivos de estudo. Adicionalmente, o professor que assume uma postura mais autônoma procura fazer reflexões a partir de textos teóricos e práticos, no intuito de ampliar seus horizontes para proporcionar a seus aprendizes práticas pedagógicas que desenvolvam as competências condizentes com as exigências contemporâneas.

$\mathrm{Na}$ última questão da enquete, buscou-se saber se as atividades realizadas por meio da WebQuest poderiam provocar mudanças na postura do professor. Os excertos 11 e 12 podem evidenciar uma vontade de mudança por parte dos participantes no tocante a suas ações pedagógicas.

[11] Podem sim, pois o professor sai de um lugar de distância com os alunos, deixa de ser o detentor do conhecimento, e passa a ser colaborador, o que pode levar a uma melhor aproximação entre eles.

(Participante 7 - Resposta ao questionário)

[12] Sim, ele deixa de ser o detentor/ transmissor do conhecimento para atuar como um mediador/ questionador/ orientador que instiga o aluno na construção de conhecimentos.

(Participante 8 - Resposta ao questionário)

Embora as relações de poder existentes nas instituições de ensino possam restringir ações autônomas tanto do aprendiz quanto do professor (ALMEIDA, 2014), é possível observar uma resistência em relação a essas imposições e um desejo de mudanças na postura do professor em prol de uma aprendizagem mais centrada no aprendiz. Podemos observar nos excertos 10, 11 e 12 indícios de uma vontade por parte dos participantes de mudar sua postura enquanto o "professor detentor de conhecimento" para o facilitador que anda ao lado do aprendiz para a construção de conhecimento, de maneira a entender a aprendizagem como um ato cognitivo e social.

\section{Considerações finais}

Ao considerar que a autonomia consiste em um fator significativo não só no processo de aprendizagem, mas em todas as práticas humanas, torna-se indispensável a promoção de atividades que possam incentivar ações autônomas de aprendizes não só no ensino de línguas, mas no ensino e aprendizagem em geral. Benson (2008, p. 25) argumenta que se entendermos "a aprendizagem como parte integrante da vida, é difícil

5 Original: "an 'adequate education' is one that leaves individuals with the capacities they need in order to lead autonomous lives" (BENSON, 2008, p. 18). 
ver como as pessoas podem levar vidas autônomas sem serem autônomas em relação ao seu aprendizado mais ou menos da mesma forma que elas são autônomas em relação às suas vidas"6. Este estudo evidenciou indícios de aspectos sociais e individuais de autonomia no processo de aprendizagem dos pós-graduandos participantes, dessa forma, é possível dizer que realizar ações autônomas não prescinde do agir cooperativamente no processo de aprendizagem. Foi possível observar, também, que a proposta por meio da WebQuest favoreceu uma postura mais autônoma tanto na perspectiva do professor quanto na do aprendiz, uma vez que os participantes apontaram para o fato de que essa proposta contribuiu para que o professor assumisse um papel de questionador, instigador e colaborador que caminha ao lado do aprendiz para juntos construírem conhecimentos.

Espera-se que os resultados deste artigo possam contribuir para o desenvolvimento dos estudos relacionados à aprendizagem autônoma e TDICs, à formação do professor, bem como à prática pedagógica de professores de línguas que se interessam por propostas de atividades que envolvam recursos digitais para promover a colaboração e a autonomia de seus aprendizes.

\section{Referências}

Al-BUSAIDI, S.; BORG, S. Learner Autonomy: English Language Teachers' Beliefs and Practices. ELT Research Paper, London, v. 12, n. 7, p. 2-50, 2012.

ALMEIDA, W. R. A. Relações de poder no cotidiano escolar: análise e reflexões da relação aluno-escola. Educação Por Escrito, Porto Alegre, v. 5, n. 2, p. 274-285, 2014.

BENSON, P. The philosophy and politics of learner autonomy. In: BENSON, P.; VOLLER, P. (ed.). Autonomy and independence in language learning. London: Longman, 1997. p. 18-34.

BENSON, P. Teachers' and learners' perspectives on autonomy. In: LAMB, T.; REINDERS, $\mathrm{H}$. (ed.). Learner and Teacher autonomy: Concepts, reality and responses. Amsterdam: John Benjamin Publishing Company. 2008. p. 15-32.

BLANCHE, P.; MERINO, B.J. Self-assessment of foreign language skills: implications for teachers and researchers. Language Learning, v. 39, n. 3, p. 313-338, 1989.

DIAS, R. WebQuests no processo de aprendizagem de L2 no meio on-line. In: PAIVA, V. L. M. (org.). Interação e aprendizagem em ambiente virtual. Belo Horizonte: Editora UFMG, 2010. p. 359-394.

DIAS, R. WebQuests: Tecnologias, multiletramentos e a formação do professor de inglês para era do ciberespaço. RBLA, Belo Horizonte, aop1212, 2012. Disponível em: http://www.scielo.br/pdf/rbla/2012nahead/aop1212.pdf. Acesso em: 15 dez. 2018.

6 Original: "if we view learning as an integral part of life, it is difficult to see how people can lead autonomous lives without being autonomous in respect to their learning in more or less the same ways that they are autonomous in respect to their lives" (BENSON, 2008, p. 25). 
DICKINSON, L. Learner autonomy: what, why and how? In: LEFFA, V. J. (ed.). Autonomy in Language Learning. Porto Alegre: Ed. Universidade/ UFRGS, 1994. p. 02-12.

FREEMAN, D.; JOHNSON, K. E. Reconceptualizing the knowledge-base of language teacher education. TESOL Quartely, v. 32, n. 3, p. 397-417, 1998.

FOUCAULT, M. Vigiar e Punir. 40 ed. Petrópolis: Vozes, 2012.

FREIRE, P. Pedagogia da autonomia: saberes necessários à prática educativa. 51. ed. Rio de Janeiro: Paz e Terra, 2015.

CHRISTIE, A. What is a WebQuest? 2007. Disponível em: http://alicechristie.org/edtech/wq/about.html. Acesso em: 08 jan. 2018.

MARCH, T. The Learning Power of WebQuests. Educational Leadership, v. 61, n. 4. p. 4247. 2004. Disponível em: http://tommarch.com/writings/ascdwebquests. Acesso em: 05 jan. 2018.

MOURA FILHO, A. C. L. O que há em um nome? O estado-da-arte da autonomia na aprendizagem de línguas. Linguagem \& Ensino. v. 12, n. 1, p. 253-283, 2009. Disponível em: http://www.rle.ucpel.tche.br/index.php/rle/article/view/104. Acesso em: 10 fev. 2018.

NÓVOA, A. Nota de abertura. In: BARBOSA, M. V. et al (org.). A Boniteza de ensinar e a identidade do professor na contemporaneidade. Campinas: Mercado de Letras, 2015. p. 11-16.

PAIVA, V. L. M. O. Autonomia e complexidade: uma análise de narrativas de aprendizagem. In: FREIRE, M. M; ABRAHÃO, M. H. V; BARCELOS, A. M. F (org.). Linguística Aplicada e Contemporaneidade. Campinas e São Paulo: Pontes e ALAB, 2005. p.135-153.

PAIVA, V. L. M. O.; VIEIRA, L. I. C. A formação do professor e a autonomia na aprendizagem de língua inglesa no ensino básico. Caderno de Resumos, XVIII ENPULI, Fortaleza, 2005. Anais... 2005.2 Disponível em: http://www.veramenezes.com/enpuli2005.htm. Acesso em 10 jan. 2018.

PAIVA, V. L. M. O. O ensino da língua estrangeira e a questão da autonomia. In: LIMA, D. C. (org.). Ensino e Aprendizagem de Língua Inglesa: conversa com especialistas. São Paulo: Parábola Editorial, 2009. p. 31-38.

OLIVEIRA, E. C. Navegar é preciso! - o uso de recursos tecnológicos para um ensinoaprendizagem significativo de línguas estrangeiras. In: PEREIRA, A. L.; GOTTHEIM, L. (org.). Materiais didáticos para ensino de língua estrangeira: processos de criação e contextos de uso. Campinas, SP: Mercado de letras, 2013, p. 185-214.

SILVA, D. J. de A. Formação de professores de língua para a autonomia: o buraco é mais 
embaixo. Trabalhos em Linguística Aplicada, Campinas, v. 52, n. 1, p. 73-92, 2013 Disponível em: http://dx.doi.org/10.1590/S0103-18132013000100005. Acesso em: 19 fev. 2018.

SINCLAIR, B. Multiple voices: Negotiating pathways towards teacher and learner autonomy. In: LAMB, T.; REINDERS, H. (ed.). Learner and Teacher autonomy: Concepts, reality and responses. Amsterdam: John Benjamin Publishing Company, 2008, p. 237-266.

WARSCHAUER, M. Computer Assisted Language Learning: An Introduction. In: FOTOS, S. (ed.). Multimedia language teaching. Tokyo: Logos International, 1996. p. 3-20.

WARSCHAUER, M. Digital literacy studies: prospects and progress. In: BAYNHAM, M.; PRINSLOO, M (eds.). The future of literacy studies. Houndmills, Basingstoke, UK: Palgrave Macmillan, 2010. p. 123-140. 